\title{
Narrativa literaria e historia, algunos puntos de debate: la concepción metahistórica de Hayden White frente a las críticas de Chris Lorenz
}

\author{
Literary Narrative and History, Some Points of Discussion: The Meta- \\ historical Conception of Hayden White against the Criticism of Chris Lorenz
}

\author{
Julián Zícari \\ sanlofas@hotmail.com \\ Doctorando \\ Universidad de Buenos Aires \\ Azcuénaga $131 / 1^{\circ} \mathrm{A}$ \\ 1029 - Buenos Aires \\ Argentina
}

\section{Resumen}

Este artículo se propone revisar la relación entre historia y literatura a partir del debate entre el narrativismo metahistórico ofrecido por Hayden White y las críticas de Chris Lorenz a dicha propuesta. Con ese fin, primero se presentarán las líneas generales de la propuesta narrativa de White, en la cual se toman premisas de la literatura y la teoría de los tropos para pensar de un nuevo modo cómo se accede al conocimiento histórico. Posteriormente, daremos lugar a varios de los reparos presentados por Lorenz respecto de problemas que, según él, son descuidados por el narrativismo al tematizar la relación entre historia y teoría estética literaria. Finalmente, una vez repasadas las posiciones de uno y otro autor, se buscará ensayar respuestas posibles a las objeciones presentadas por Lorenz, no para zanjar la discusión sobre el tema, sino para mantener en vigencia varios de los puntos en disputa desde otras perspectivas. Se finalizará el artículo con algunas conclusiones al respecto.

\section{Palabras clave}

Narrativas; Positivismo; Metodología.

\begin{abstract}
This article revisits the relation between history and literature in the debate between metahistorical Narrativism as presented by Hayden White and the criticisms of Chris Lorenz to its proposal. To attain this goal, the article firstly presents the outlines of White's narrative proposal, in which assumptions of the literature and theory of tropes are used to think a new way of accessing historical knowledge. Next, it presents several objections presented by Lorenz regarding problems that, in his view, are overlooked by Narrativism in its approach to the relation between history and literary aesthetic theory. Finally, after examining both positions, the article seeks to test possible answers to the objections raised by Lorenz, not as an attempt to settle the debate on the subject, but, instead, to maintain the validity of several disputed points from other perspectives. The article ends by presenting some conclusions on the theme.
\end{abstract}

Keywords

Narratives; Positivism; Methodology.

Recibido el: 26/7/2014

Aceptado el: 11/11/2014

\footnotetext{
${ }^{*}$ El autor quiere agradecer muy sinceramente los comentarios, sugerencias y observaciones de los evaluadores anónimos, los cuales han enriquecido este trabajo. Esta investigación ha sido financiada por el Consejo Nacional de Investigaciones Científicas y Técnicas (Conicet).
} 


\section{Un debate entre tropos, tramas y objeciones}

Hace ya 25 años David Harlan señaló, en un recordado y polémico artículo, que "el retorno de la literatura ha sumido a los estudios históricos en una extendida crisis epistemológica" (HARLAN 1989, p. 581, traducción nuestra). ${ }^{1}$ De este modo, se señalaba que el cruce entre la literatura y la historia necesariamente iba a comprometer nuestra mirada sobre un pasado considerado inmóvil y determinable, replanteando así nuestras posibilidades de representación histórica y poniendo en cuestión nuestra capacidad de ubicarnos a nosotros mismos en el tiempo (HARLAN 1989, p. 581). Si bien las premisas de Harlan fueron rápidamente discutidas y cuestionadas (HOLLINGER 1989, p. 610-621), lo que es cierto es que las tensiones del cruce entre historia y literatura no han dejado de problematizarse. Por un lado, porque tal cruce nos ha provisto de un terreno fértil para repensar nuestra vinculación con el pasado y, por otro, porque las rutas que habilitó no han dejado de ofrecer también nuevos problemas, sobre todo en el plano teórico y epistemológico (CARR 1993). En ese sentido, en este trabajo no se intentará revisar todos los problemas y tensiones del cruce entre literatura e historia, sino tan sólo se buscará poner en diálogo a dos autores, buscando repasar los términos de su debate.

Así, en primer lugar, intentaremos presentar la propuesta metahistórica de Hayden White, en la cual señala que nuestro acceso y construcción del conocimiento histórico están dados por su estructura narrativa. Frente a esa mirada, trataremos de contraponer los reparos presentados Chris Lorenz,

128 quien, mediante diversos argumentos, cree invalidar la mirada presentada por White señalando varias debilidades de su enfoque. Es así que, a continuación, buscaremos ofrecer respuestas tentativas que, desde el narrativismo, se pudieran dar a los planteos de Lorenz. En este caso, los señalamientos que presentaremos no buscarán dirimir los puntos en disputa, sino simplemente brindar elementos para la discusión. Finalmente, el trabajo ofrecerá algunas conclusiones con vistas a nuevas formulaciones que podrían continuar el debate presentado.

\section{El narrativismo de Hayden White: entre la metahistoria y la literatura}

La historia es la narración de los hechos tenidos por verdaderos. Voltaire

Hayden White irrumpió fuertemente en la escena intelectual del conocimiento histórico a mediados de los años 1970 con su célebre Metahistoria. La imaginación histórica en la Europa del siglo XIX (2010). En este caso, su original conclusión fue señalar que la obra histórica era por sobre todas las cosas "una estructura verbal en forma de discurso en prosa narrativa" (WHITE 2010, p. 9). En decir, lo que hizo fue señalar que la relación entre narración y conocimiento histórico no puede trivializarse, ya que la vinculación entre ambos ha distado mucho de ser transparente.

\footnotetext{
${ }^{1}$ En el original: "The return of literature has plunged historical studies into an extended epistemological crisis".
} 
En efecto, según White, el canon dominante de la historiografía tradicional (Tocqueville, Burckahardt, Braudel, etc.) Ilamó a rechazar la narración como elemento constitutivo del sentido histórico, puesto que esos autores suponían que la realidad que percibían no era narrativizada al configurar un relato histórico, sino que era un discurso que relataba directamente el mundo que decían percibir. De esa forma, la historiografía tradicional entendía que usaba la narración sólo como una herramienta subordinada y no como aquello constituyente de sus relatos y sentidos. En cambio, para White, precisamente, es necesario revisar el lugar que se le dio a la narrativización a fin de conformar conocimiento histórico: ésta no debe ser relegada a un papel de simple herramienta periférica, destinada a la invisibilización, sino, más bien, ocupar un rol central a la hora de abordar el conocimiento histórico. Es decir, según White, si el pasado, por definición, no es observable en forma directa, debe ser reconstruido narrativamente por los historiadores bajo una presentación formal-teórica similar a la utilizada en el campo de la literatura, ya que es ese mismo relato el que le da forma a los hechos del pasado. ${ }^{2}$ Señala White (2010, p. 42): "[e]s imperativo, por lo tanto, cuando se analizan representaciones supuestamente 'realistas' de la realidad, determinar el modo poético dominante en que está expresado su discurso".

En esa dirección, para White, el problema de la narrativización en historia debe pensarse en función de cómo se traduce el conocimiento en relato; es decir, se trata del problema de configurar la experiencia humana en una forma asimilable a estructuras de significación para que aquélla adopte un orden de sentido. Así, para White, la narrativa es un metacódigo que, al estructurar aquello que cuenta, lo configura: construye con su propia trama el orden y la coherencia, estableciendo su sentido. De esa forma, la falta de narrativa o su rechazo pueden equivaler a la ausencia misma de significación. Es por eso que, para White, las partes intervinientes de la narración - por ejemplo, la información histórica suministrada-, al conformar la trama y ser parte de ella, logran su propia forma comprensiva y comprensible, ya que las narraciones dependen, no sólo de la visión político-moral del pasado propia del historiador, sino, y principalmente, de la forma verbal (poética o literaria) con la que se construyen. ${ }^{3}$

En ese sentido, para White, la narrativa, al darle la forma a los relatos, funciona como una imposición de aquello que establece; es decir, le da una imposición al relato en la medida en que la representación de los acontecimientos, hechos y personajes intervinientes es animada por una pretensión de verdad y ellos están entrelazados por la forma lógica que los implica. Su emergencia y

\footnotetext{
${ }^{2}$ No viene mal recordar la ya clásica cita de otro importante narrativista, el holandés Frank Ankersmit (1981, p. 19): "Más cercana a la narración está la novela y, entre todos los tipos de novela, por supuesto, es la novela histórica la que más se acerca a la narración". White señala algo parecido y en la misma dirección: "Yo he invertido, en cierto sentido, su formulación [la de historiografía tradicional]. Ellos preguntan: ¿cuáles son los componentes 'históricos' de un arte 'realista'? Yo pregunto: ¿cuáles son los elementos 'artísticos' de una historiografía 'realista'?" (WHITE 2010, p. 18 n. 4).

3 Señala White (2010, p. 15): "[la] posición [de los relatos históricos] como posibles modelos de representación o conceptualización histórica no depende de la naturaleza de los 'datos' que usaron para sostener sus generalizaciones ni de las teorías que invocaron para explicarlas; depende más bien de la consistencia, la coherencia y la fuerza esclarecedora de sus respectivas visiones del campo histórico. Por eso no es posible 'refutar' o 'impugnar' sus generalizaciones [...] Su categorización como modelos de narración y conceptualización históricas depende, finalmente, de la naturaleza preconceptual y específicamente poética de sus puntos de vista sobre la historia y sus procesos".
} 
despliegue se constituye en el relato mismo del que forman parte. La narrativa, con su propia forma, les impone a ellos la suya junto a sus vinculaciones. Así, la narrativa histórica, "al hablar por sí misma", se expresa mediante una modalidad significativa de su propia trama: aquello narrado. De esa manera, los elementos del relato no sólo son configurados por la narración, sino que emergen de la estructura de la trama, estando subordinados a ella. Es por eso que la relación entre escritura, teoría literaria de los tropos y discurso cobra un particular interés a la hora de entender nuestra relación con el pasado -la cual no debe descuidarse- y cómo figuramos éste último. ${ }^{4}$ Eso es así porque, como en la literatura, los hechos históricos que se narran y la forma en que se los trama no se distinguen, de modo que las dicotomías tales como forma y contenido (o el qué frente al cómo) se disuelven constituyendo el propio relato expresado (de ahí el título de un libro de White, El contenido de la forma).

Gracias a la trama narrativizada, la realidad adquiere un aspecto de regularidad y orden (una coherencia de sentido) que, como dijimos, al ser impuesta por el relato, presenta un aspecto de globalidad e integridad en la historia que es en última instancia lo que el discurso sobre el conocimiento histórico pretende establecer. Escritura, análisis y estructuras se implican mutuamente y no pueden ya desvincularse. Parafraseando a Kant, White señala que "las narraciones históricas sin análisis son vacías y los análisis históricos sin narrativas son ciegos" (WHITE 1992, p. 21), ya que la narrativización implica que los enunciados individuales que compone no puedan retener su significación por fuera de ella: cualquier representación "fáctica" debe ser figurada e incorporada a un relato para no perderse en el caos y la anarquía del sinsentido. Estos sucesos y hechos son "seleccionados" por medio de un recorte que construye el relato narrativo: su inicio, modo de vinculación, forma de resolución, etc., son implicados en cada caso según un juzgamiento estético/moral del historiador. ${ }^{5}$ Señala White, así, que el conocimiento histórico se produce bajo la forma de la teoría trópica del relato de cuatro maneras: 1) su tipo de prefiguración (metáfora, metonimia, sinécdoque e ironía), 2) su modo de tramar (romántico, trágico, cómico y satírico), 3) su manera de argumentar (formista, mecanicista, organicista y contextualista) y 4) en relación con formas de implicación ideológica (anárquica, radical, conservadora y liberal) (WHITE 2010, p. 39). En este caso, entonces, los diversos tropos se articulan entre sí para conformar una trama particular, sin ser las diversas variantes trópicas modos exhaustivos de cada una, pudiendo existir otras. En esa dirección, señala White que las elecciones de cada tipo de tropo por parte de un historiador "sirven como presuntas leyes de

\footnotetext{
${ }^{4}$ Frente a las objeciones que acusan al narrativismo de solo determinar, con la recuperación de la literatura en la historia, la primacía del lenguaje y del discurso como mero mentalismo, White señala: "La tropología es una teoría del discurso, no de la mente o de la conciencia. Aunque supone que no se puede evitar la figuración en el discurso, la teoría, lejos de implicar un determinismo lingüístico, busca proporcionar el conocimiento necesario para una libre elección entre diferentes estrategias de figuración" (WHITE 2003, p. 171).

5 Dice White: "en la medida en que un historiador proporciona una 'trama' que da algún tipo de coherencia formal a los sucesos del relato que narra, está haciendo lo mismo que hace el científico cuando identifica los elementos de la argumentación nomológico-deductiva en que debe organizar su explicación" (WHITE 2010, p. 23).
} 
explicación histórica" (WHITE 2010, p. 22), ${ }^{6}$ conformando el verdadero marco conformativo del conocimiento histórico. La estructura narrativa es, de este modo, la verdadera metahistoria del relato, constituye las condiciones de posibilidad del cual emerge. Así, para White, el historiador,"[h]ace su relato incluyendo algunos hechos y excluyendo otros, subrayando algunos y subordinando otros. Este proceso de exclusión, acentuación y subordinación se realiza con el fin de constituir un relato de un tipo particular. Es decir, el historiador 'trama' su relato" (WHITE 2010, p. 17).

De esa forma, cada "recorte del relato histórico" demandará una moralización estética efectuada por medio de su tipo de narrativa. Según la visión de White, la representación de los hechos históricos deberá apelar a la narrativa (y su juzgamiento moral) si deseamos que tales hechos tengan la coherencia, integridad, plenitud y cierre que les atribuimos (y necesitamos atribuirles) para considerar el conocimiento histórico como una disciplina. No es cuestión de discutir si los hechos narrativizados son o no ficcionalizados de forma tal que se evada la realidad, ya que, según White, "[s]i sólo fuese realismo de presentación, podría defenderse considerablemente la modalidad de los anales y la crónica como paradigma de forma en que la realidad se presenta a la percepción" (WHITE 1992, p. 37). Eso no ocurre actualmente en el discurso histórico, como, a su vez, tampoco exime a dichos procedimientos de elementos morales y/o estéticos. Como lo demuestra exquisitamente White, aun los anudamientos de proposiciones meramente descriptivas como los que se observan en las crónicas y anales y que, intuitivamente, se podría pensar que fueran neutrales en términos ideológicos/morales, igualmente conforman una mirada sobre el mundo que no es de ningún modo aséptica (WHITE 1992, Cap. 1), sino presa de sus propios presupuestos estéticos, morales y políticos. Por eso, es la creación de la trama narrativa la verdadera operación intelectual que permite vincular los hechos aislados - acontecimientos- y aportarles un sentido, realizando una "síntesis de lo heterogéneo". Así, la historia, según la narrativa, es un cruce de caminos entre los conceptos (juzgamientos morales, estéticos, ideológicos, etc.) y hechos de referencia, "fácticos", que son expresados por medio del relato construido por el historiador y que se ofrece como una representación posible de una parte del pasado.

\section{Los límites al narrativismo: las críticas de Chris Lorenz}

En la historia, una vez eliminada la verdad, resulta un relato inservible. Polibio

Chris Lorenz ha buscado invalidar varias de las tesis sostenidas por el narrativismo de White. El autor señala que la caracterización de las narrativas

\footnotetext{
${ }^{6}$ En otra obra señala: "No hay necesidad, lógica o natural, que gobierne la decisión de tramar una secuencia dada de acontecimientos como una tragedia más que como una comedia o un romance [...] Ello se debe a que los relatos no son vividos; no hay relatos reales. Los relatos son contados o escritos, pero no encontrados" (WHITE 2003, p. 156).
} 
históricas como "ficcionales" y/o "metafóricas" no es pertinente. Lorenz (1998, p. 310) entiende que a partir del narrativismo la filosofía de la historia se ha alejado de la filosofía de las ciencias y de la ciencia social para acercarse a la filosofía del arte, la literatura, la retórica y la estética, descuidando importantes aspectos metodológicos de su propia disciplina. Por ejemplo, según Lorenz, en su celo por corregir la tradicional forma de identificación de la historia profesional con algunos aspectos del positivismo clásico, el narrativismo terminó omitiendo por completo la investigación histórica de las características que identifican la disciplina. De ese modo, realizó, paradójicamente, una inversión en la cual retiene aquello que combate sin modificar los términos del debate. Para presentar el punto de vista de Lorenz, he reconstruido sus argumentos críticos sobre el narrativismo metafórico agrupándolos en cinco tipos.

El primer argumento crítico contra el narrativismo se basa en rechazar su afirmación de que la forma de la narrativa histórica debe dejar de lado una noción de verdad como "correspondentista". En este caso, según Lorenz, el narrativismo, para sostener esa tesis, debe apelar a la forma lógica del "o bien o bien" [either-or logic], según la cual los usos del lenguaje sólo podrían ser de dos tipos: o bien "el literal", o bien "el figurado". Esta distinción es retenida de los planteos positivistas, pero ahora valorada del modo inverso: mientras antes el positivismo privilegiaba los enunciados "con datos" y subordinaba lo figurativo a "mero palabrerío", el narrativismo asciende el lenguaje metafórico al núcleo articulador de lo real, reemplazando así empirismo por estética al relegar "Ios datos" a mera descripción (LORENZ 1998, p. 310).7 De esa forma, sigue sosteniendo la dicotomía entre observación empírica "objetiva" e interpretación "subjetiva". Así, según Lorenz, el narrativismo termina por negar la pretensión de verdad de la narrativa histórica, cometiendo un gran error, ya que la historia, para ser una disciplina como tal, no puede desmerecer su base empírica y la relación con los datos, si es que no quiere convertirse en una mera forma de arte más. El autor concluye señalando críticamente que "sin el empirismo, simplemente no hay argumentos plausibles para los principios básicos del narrativismo metafórico" (LORENZ 1998, p. 315, traducción nuestra). ${ }^{8}$

El segundo argumento crítico contra el narrativismo se basa en no aceptar tampoco la propuesta narrativa de que las metáforas narrativas son autoexplicativas por sí mismas; esto significaría que toda explicación por narrativa excluiría así a las explicaciones causales. En efecto, cuando se afirma esto, en última instancia, se termina realizando una nueva inversión de las premisas positivistas, reteniendo igualmente sus esquemas. Si el positivismo señalaba que sin causas no es posible establecer explicaciones, para el narrativismo

\footnotetext{
7 Del mismo modo, Lorenz señala que el narrativismo lleva, incluso, la forma lógica del "o bien o bien" hasta un extremo: "o bien las afirmaciones del conocimiento pueden ser firmemente fundadas en datos empíricos, o bien las exigencias de conocimiento son arbitrarias y un mero producto de la imaginación. Se supone así que [para el narrativismo] la fantasía es la única alternativa para la única oposición al fundamento" (LORENZ 1998 , p. 313 , traducción nuestra, cursivas de Lorenz). En el original: "either knowledge claims can be firmly founded in empirical data, or claims to knowledge are arbitrary and a sheer figment of imagination. Fantasy is thus presupposed to be the only alternative for and only opposition to foundation".

8 En el original: "without empiricism there simply are no plausible arguments for the basic tenets of metaphorical narrativism".
} 
(sobre todo en la versión de Ankersmit), ocurre lo opuesto: cualesquiera que sean las conexiones explicativas, los vínculos no son causales por sí mismos, sino que están dados por el relato (LORENZ 1998, p. 318). Así, el narrativismo, al rechazar el modelo de cobertura legal, debió adherir a su reverso: "aceptar una variedad ilimitada de explicaciones narrativas empíricamente indecidibles y la sustitución de criterios epistemológicos por criterios estéticos" (LORENZ 1998 , p. 323, traducción nuestra). ${ }^{9}$ De igual modo, el narrativismo tampoco en este caso lograría salir, una vez más, de la forma lógica binaria del "o bien o bien" retenida del positivismo. Como lo señala Lorenz:

o bien la narrativa del historiador es un simple subproducto de la investigación, como lo habría considerado la visión positivista "tradicional", o bien no tiene en absoluto nada que ver con la investigación. $O$ bien las narrativas de los historiadores están empíricamente fundadas como lo habría considerado la visión positivista "tradicional"- o bien las narrativas históricas no tienen en absoluto fundamentos empíricos y son un producto de la imaginación histórica. $O$ bien el lenguaje es transparente y referencial vis-a-vis la realidad - como lo habría considerado la visión positivista "tradicional" - o bien el lenguaje es autorreferencial y opaco (1998, p. 314, traducción nuestra, cursivas de Lorenz). ${ }^{10}$

La tercera crítica se centra en señalar que el narrativismo no da el "sendero de la ciencia verdadera" [The Path of Real Science], es decir, no ofrece una fórmula general que funcione como forma prototípica de la construcción de relatos (LORENZ 1998, p. 319) porque supone que no vale la pena hacerlo, ya que considera que toda construcción lingüística narrativizada impone a los hechos sus propias formas frente al caos. Así, al no privilegiar un procedimiento o dar pautas metodológicas valorativas específicas, el modo en que los tropos y estructuras de las tramas deben ser considerados como explicativos no resulta evidente, siendo esta una importante falencia metodológica. En este caso, ese descuido del narrativismo bloquearía formas comparativas (y objetivas) que nos indiquen cuándo la obra de un historiador es mejor que la de otros, destacando los trabajos importantes de aquellos que no lo son. De esa manera, sin procedimientos de validación pautados, cada narrativa estaría en pie de igualdad con las demás y se perderían los parámetros críticos de la disciplina.

La cuarta crítica al narrativismo señala que éste contrasta y enfrenta "conocimiento" con "interpretación", identificando a ésta última con narrativización/ficcionalización, lo cual lo llevaría, en última instancia, a un abandono de la epistemología y la racionalidad (LORENZ 1998, p. 327). Así, según Lorenz, el problema fundamental de White y del narrativismo en general ${ }^{11}$

\footnotetext{
${ }^{9}$ En el original: "embracing an unlimited variety of empirically undecidable narrative explanations and the replacement of epistemological by aesthetic criteria".

10 En el original: "either the narrative of the historian is a simple by-product of research, as the "traditional," positivistic view would have it, or it has nothing to do with research at all. Either the narratives of historians are empirically founded-as the "traditional," positivistic view would have it-or historical narratives have no empirical foundations at all and are the product of literary imagination. Either language is transparent and referential vis-àvis reality-as the "traditional," positivistic view would have it-or language is self- referential and opaque".

${ }^{11}$ Es necesario señalar que gran parte del análisis crítico realizado por Lorenz está dirigido al narrativismo como un todo y que una de las mayores dificultades de lectura que impone su artículo -y su producción- reside en la confusa y descuidada mixtura que realiza de los argumentos de White y de Ankersmit alternativamente
} 
es su alianza inquebrantable con el fundacionalismo y -finalmente- con el escepticismo (aquí el escepticismo sería una consecuencia lógica frente a las "arbitrariedades" de cualquier selección estética/moral, ya que no habría, finalmente, "fundamentos sólidos últimos"). De ese modo, señala Lorenz (1998, p. 321) que, como el narrativismo rechaza cualquier fundamento, dado su "antirreduccionismo" (porque identifica conocimiento fundamentado con "absoluto"), sólo nos ofrece como contraposición la "fantasía y la imaginación" (LORENZ 1998, p. 313) y una fuga hacia el arte. Así, esa 'libertad artística' [artistic freedom], como la llama Lorenz, sin restricciones, dejó al narrativismo gravemente enfermo de subjetivismo, olvidando que la historia es una disciplina con controles intersubjetivos que requiere criterios epistémicos para sus validaciones. Por eso, una vez más, el narrativismo conservaría la dicotomía profunda del positivismo al contraponer observación empírica "objetiva" a interpretación "subjetiva" (LORENZ 1998, p. 314).

Finalmente, como quinta crítica, Lorenz sostiene que la diferencia entre "enunciados individuales" y "narrativas completas" es, a diferencia de lo que sostiene el narrativismo, una diferencia de grado y no de naturaleza (LORENZ 1998 , p. 325). Según el autor, las narrativas no pueden ser simplemente presentadas o "relatadas" sin más, sino que requieren un apoyo tanto empírico como lógico para poder ser aceptadas. Por eso, no pueden desconectarse de su contenido referencial en el uso del lenguaje por la mera ficcionalización, como tampoco hacerlo en pro de la relación entre la investigación histórica y su escritura (según Lorenz, un importante descuido del narrativismo). En efecto, no se puede despojar al campo histórico de su base empírica, convertido en tan sólo retórica y/o escritura.

\section{Respuestas posibles frente a las objeciones}

El historiador es necesariamente selectivo. La creencia en un núcleo óseo de hechos históricos existentes objetivamente y con independencia de la interpretación del historiador es absurda, pero dificilísima de desarraigar [...] En general, puede decirse que el historiador encontrará la clase de hecho que busca. Historiar significa interpretar.

Edward H. Carr

En este apartado intentaré aportar nuevas consideraciones con respecto a los planteos de Lorenz, buscando extraer de las críticas señaladas al narrativismo algún tipo de respuesta válida. En pos de ello, buscaré dar elementos que permitan conferir mayor fertilidad al debate, permitiendo que siga vivo al relanzar los términos de la discusión. Para eso, intentaré esbozar nuevos argumentos que mantengan vivos los nudos problemáticos de la polémica.

Vimos que la primera crítica de Lorenz busca señalar que el narrativismo termina cayendo en antinomias inconvenientes que se encuentran atrapadas

y según convenga a sus propósitos críticos. Eso no sólo se nota en la falta de citas para sostener algunas de sus caracterizaciones, sino también en la construcción de un esbozo general del narrativismo, al cual atribuye varias proposiciones genéricas que, luego, indebidamente, pretende rebatir con sus argumentos. 
bajo la forma lógica del "o bien o bien". En efecto, el narrativismo realizaría una inversión del positivismo sin dejar de lado sus esquemas: en vez de valorar por sobre todo "los datos", privilegiaría el relato. Creo que el "correspondentismo" que señala Lorenz no sería válido dentro de la perspectiva narrativista; primero, porque no estoy de acuerdo con que White o algún otro narrativista señalen dicotomías entre su base empírica y la narración, ya que el postulado básico es, justamente, el de que la propia forma narrativa es la que produce y permite integrar los datos históricos que intenta explicar. En ese sentido, si bien puede haber cierta demarcación entre un "dato" y la estructura de su relato, creo que cuando se lo delimita es desde un presupuesto explícito: no serían una dualidad excluyente en la que "hechos" y "palabras" tuvieran caminos separados que habría que hacer "corresponder" según un tipo de formulación, sino, en todo caso, un dualismo inclusivo, del mismo tipo que, en las explicaciones históricas, lo son "estructura y coyuntura" o también "sujeto e institución". En efecto, se trata en este caso de dualismos como elementos que conforman partes integrantes y que (co)pertenecen el uno al otro (por ejemplo, los sujetos no son algo distinto de las instituciones a las que pertenecen y viceversa) (VILAR 1980 , p. 95). De hecho, para el narrativismo no hay una diferencia "ontológica" entre la dimensión fáctica y su figuración: no son dos ámbitos heterogéneos que habría que hacer coincidir, sino tipos de codificación que la misma trama histórica busca constituir en un mismo movimiento (TOZZI 2009a, p. 114). ${ }^{12}$

Con respecto a la segunda crítica, en la cual Lorenz señala que el narrativismo deja de lado los nexos causales como forma explicativa en pos de basarse en la "libertad artística" para construir relatos, creo que en ella también hay un presupuesto epistemológico en disputa. En efecto, como lo han señalado varios autores, las ciencias sociales no pueden recurrir a la misma metodología que las denominadas "ciencias duras", como la física o la biología, que apelan a leyes universales y condiciones iniciales constantes para ratificar (o refutar) sus postulados. En el caso de la historia eso no es posible, ${ }^{13}$ ya que sólo cuando tenemos todas las condiciones para producir un hecho como la revolución francesa es posible "obtener" como resultado la Revolución Francesa misma. En ciencias sociales no hay leyes universales explicativas, ni hay una lógica trascendente que pueda regular las lógicas históricas. Por eso, más que lograr explicaciones dentro de los esquemas de cobertura legal, lo mejor que se puede obtener son comprensiones sobre los procesos lo más logradas posible. En ese sentido White considera que los relatos históricos se ven, necesariamente, obligados a hacer elecciones entre estrategias interpretativas posibles (bajo las articulaciones de los tropos), siendo esas elecciones muchas veces rivales entre sí. Al respecto, dice White, sobre la conformación de la producción que nos permite acceder al pasado: "esto significa que las explicaciones históricas tienen que basarse en distintos presupuestos metahistóricos sobre la naturaleza del campo histórico,

\footnotetext{
12 Es interesante notar que el mismo Putnam, al que Lorenz dice estar siguiendo, separa entre dualismo y dicotomía en una diferenciación similar a lo que nosotros llamamos "dualismo excluyente" y "dualismo incluyente".

13 Una reposición sobre este debate se puede encontrar en TOZZI 2009b.
} 
presupuestos que generan distintas concepciones del tipo de explicaciones que pueden utilizarse en el análisis historiográfico" (WHITE 2010, p. 23). Y agrega posteriormente: "No puedo afirmar que una de las concepciones del conocimiento histórico favorecida por determinada ideología sea más 'realista' que las demás, porque justamente en lo que discrepan es en la cuestión de qué es lo que constituye un criterio adecuado de 'realismo'" (WHITE 2010, p. 36).

Con respecto a la que he señalado como tercera crítica de Lorenz al narrativismo (en la cual éste no ofrecería una propuesta valorativa con respecto a la producción y a la metodología, sin privilegiar un procedimiento frente a otro), creo que se liga directamente a lo recién destacado. En todos los casos, creo que las propias pautas de valoración de una narración son las que permiten apreciar sus logros o invalidarlos. Los criterios estéticos y tropológicos no pueden ofrecer por sí mismos una referencia a priori para su formulación, ya que, en cada caso, los receptores podrán sentir mayor o menor afinidad con las elecciones estético-morales realizadas; pero lo que no es de ningún modo aceptable para el narrativismo es alguna premisa metahistórica que pudiera vislumbrarse como plenamente "neutral" y que sea irrestrictamente válida. Así, señala White:

[e]n mi opinión, no hay terreno extraideológico en el cual juzgar entre concepciones rivales del proceso y el conocimiento histórico que las ideologías invocan. Porque, como tales concepciones tienen su origen en consideraciones éticas, la adopción de determinada posición epistemológica por la cual juzgar su adecuación cognoscitiva no representaría más que otra elección ética (2010, p. 36).

Y remata después: "[no] puedo afirmar que una concepción del conocimiento histórico sea más 'científica' que las demás sin prejuzgar el problema de cómo debería ser una ciencia específicamente histórica o social".

Así, la viabilidad y/o aceptación de los relatos no depende de algún "sendero de la verdad científica" preestablecido, como le gustaría a Lorenz, sino de la propia forma de configuración de la trama narrativa. En ese sentido, creo que el narrativismo no desmerece la base empírica y/o los criterios metodológicos. En todos los casos, son importantes éstos como argumentos críticos a la hora de valorar una investigación frente a otra. Sin embargo, nunca terminan por ser perentorios. Al igual que en las "ciencias duras", las interpretaciones son falseables, refutables, y pueden perder consenso tan rápido como lo adquirieron, como también, por más que existan en algunos casos consensos mayoritarios y/o hegemónicos, éstos son tan frágiles como en dichas ciencias, nunca llegando a ser absolutos. De esa manera, no me parece que el narrativismo se desentienda de la pretensión de verdad en historia, sólo señala que la forma de establecer dicha pretensión dependerá de la propia fuerza del relato construido y de los elementos a los que apela en la conformación de su trama (capacidad heurística, base empírica, análisis crítico, rigor metodológico, complejidad sociopolítica, etc.). Por eso, el valor de una narrativa no ofrece como único criterio la "libertad artística", como se sugiere, sino un proceso bastante más complejo. El mismo White señala que " $[u] n$ verdadero relato narrativo, $[. .$.$] es menos un producto$ 
del talento poético del historiador, tal como se concibe la presentación narrativa de los acontecimientos imaginarios, que el resultado necesario de una aplicación correcta del 'método' histórico" (WHITE 1992, p. 42-43).

Si tenemos en cuenta que, como lo señalé al presentar la cuarta crítica al narrativismo, Lorenz entiende que el narrativismo enfrentaría con sus postulados "conocimiento" con '"interpretación", oponiendo así "criterios objetivos" a apreciaciones "subjetivas y estéticas", las consecuencias que se desprenderían de ello serían simplemente el abandono de toda epistemología y racionalidad. Creo que ese desacuerdo es uno de los puntos claves del debate. Por ejemplo, tratemos de postular una premisa básica del narrativismo: ningún historiador discute hechos, fechas y acontecimientos; la base "empírica" tal como la distingue Lorenz, en general, es aceptada por todos. Nadie discute que Salvador Allende fue derrocado en 1973 o que Colón llegó a América en 1492. Lo que suele estar en disputa es cómo vincular esos hechos y qué peso tienen sus explicaciones. No es lo mismo señalar que el agotamiento del patrón de acumulación de la segunda postguerra se debió a los aumentos bruscos del precio del petróleo que responsabilizar por eso a "los altos salarios" de los trabajadores, que hacían reducir la rentabilidad del capital. En ese sentido, para el narrativismo, es la interpretación la responsable de configurar las relaciones entre los elementos, aplicándoles una carga valorativa diferencial en cada caso interpretativo. Hay siempre, como el mismo Lorenz reconoce, una "carga teórica de las pruebas": una valoración dependerá, en última instancia, de disposiciones morales, políticas y estéticas no reducibles a reconciliación racional (lo cual no implica irracionalismo o ausencia de fundamentos en cada caso).

En la misma dirección, creo que el narrativismo no renuncia a la pretensión de verdad en la historia, o más bien, no renuncia a señalar la existencia misma del pasado, sino que tan sólo intenta problematizar cómo se accede a él: la disputa es sobre qué entendemos por realidad histórica y sobre cómo la configuramos. De ese modo, no supone - una vez más, como lo afirma Lorenz- que "la libertad artística" sea irrestricta, sino que las limitaciones están dadas por el propio campo histórico: una narrativa muy poco verídica, alejada de los hechos históricos compartidos, que establece relaciones poco operativas, sin argumentaciones sólidas o carente de base epistémica alguna, tiene muy pocas chances de ser aceptada. Por otro lado, el problema de la separación entre "interpretación" y "conocimiento" que Lorenz le objeta al narrativismo me parece que no puede sostenerse como tal, puesto que, precisamente, el planteo de White se esfuerza por evitar el establecimiento de una relación de oposición o condicionamiento entre una cosa y la otra. Así, no puede haber enfrentamiento o privilegio alguno que pueda ser concedido a instancia alguna, sencillamente porque no hay dos cosas en contraposición. "Las disputas historiográficas sobre el nivel de 'interpretación'", dice White, "son en realidad disputas sobre la 'verdadera' empresa del historiador" (WHITE 2010, p. 23).

Finalmente, esto último nos sirve para intentar responder a la quinta crítica de Lorenz al narrativismo, dirigida principalmente contra el antirrealismo de Ankersmit, para lo cual podemos tomar un clásico razonamiento propuesto por Platón. Si, para Platón, es la idea del Bien la que le permite al intelecto acceder 
"a la verdad", en forma análoga a como la luz del Sol es la responsable de que los ojos puedan ver, en nuestro caso, creo que son las narrativas completas las que iluminan los enunciados singulares y nos permiten reconocerlos a la luz de su interpretación. ${ }^{14}$ Del mismo modo, recuperando el perspectivismo nietzscheano, podemos afirmar que nunca hay tan sólo hechos, sino interpretaciones de ellos. En efecto, las narrativas completas funcionan como una suerte de efecto gestalt total, donde el todo es mayor que la suma de sus partes. Como dijimos antes, para el narrativismo, los relatos no pueden ser evaluados exclusivamente en términos lógicos ni descomponerse en enunciados simples o complejos, ya que su estructura es la trama que les da sentido. Por eso, los datos "desnudos" en sí mismos, si acaso pudieran existir, son incapaces de determinar nuestra forma de entender el pasado: siempre necesitamos alguna configuración de sentido o forma de discurso - una narrativa - para representarnos la historia. ${ }^{15}$

\section{A modo de cierre}

La historia es el producto más peligroso que haya elaborado la química del intelecto [...] La historia verifica lo que uno quiere, no enseña rigurosamente nada, porque contiene todo y da ejemplos a todos.

Paul Valéry

A lo largo de este trabajo he intentado reponer los términos del debate entre la propuesta narrativista de Hayden White y los reparos críticos de Chris Lorenz. He buscado presentar las respectivas posiciones y buscar dar algún tipo de respuesta a las objeciones de Lorenz. Igualmente, una vez realizado esto, creo que el narrativismo debe poder reforzar algunos de los puntos débiles señalados por Lorenz. ${ }^{16} \mathrm{~A}$ su vez, en todos los casos, me parece que es necesario recuperar los diversos puntos debatidos, relanzando los términos en discusión, para así intentar alcanzar una mejor aproximación sobre nuestro pasado.

\section{Referências bibliográficas}

ANKERSMIT, Frank. Narrative Logic. A Semantic Analysis of the Historian's Language. Groninjer: Martinius Nijhoff, 1981.

CARR, Graham. Literary History: Convergence or Resistance? Acadiensis, v. XXIII, n. 1, p. 159-179, 1993.

HARLAN, David. Intellectual History and the Return of Literature. American Historical Review, v. 94, n. 3, p. 581-609, 1989.

\footnotetext{
${ }^{14}$ Heidegger utiliza la famosa "alegoría del sol" de Platón (República 506e) para señalar que todo conocimiento finalmente tiene una premisa de valor moral como su presupuesto. En efecto, Platón traza la analogía señalando que, así como el ojo reconoce los objetos porque existe la luz del sol que ilumina, posibilitando ver, así el intelecto reconocería lo verdadero porque la idea del Bien se lo permitiría. Es decir, el filósofo se basa en un razonamiento circular principalmente moral: es, ante todo, porque reconocemos qué es el Bien que podemos reconocer lo verdadero; así el "mundo" pasa primero por los "valores" (HEIDEGGER 1953, p. 20). ${ }^{15}$ Señala White (2010, p. 14): "consideraré la obra histórica como lo que más manifiestamente es: es decir, una estructura verbal en forma de discurso de prosa narrativa que dice ser un modelo, o imagen, de estructuras y procesos pasados [...] Mi método, en suma, es formalista".

${ }^{16}$ Recordemos que Lorenz no siempre ha sido tan crítico con el narrativismo, adscribiendo en muchos casos a varios de sus postulados. Ver (LORENZ 1994).
} 
HEIDEGGER, Martín. Doctrina de la verdad según Platón. Santiago de Chile: Arcis, 1953.

HOLLINGER, David. The return of the Prodigal: The Persistence of Historical Knowing. American Historical Review, v. 94, n. 3, p. 610-621, 1989.

LORENZ, Chris. Historical Knowledge and historical reality: a plea for internal realism. History and Theory, n. 33, 1994.

. Can Histories be true? Narrativism, Positivism and the 'Metaphorical Turn'. History and Theory, v. 37, n. 3, 1998.

NAISHTAT, Francisco. Refocalización historiográfica y cambio de régimen de historicidad. In: NUDLER, Oscar (dir.) Espacios controversiales. Hacia un modelo filosófico y científico. Bs. As.: Miño y Dávila, 2009.

RICOEUR, Paul. La lectura del tiempo pasado: memoria y olvido. Madrid: Arrecife, 1999.

SCHUSTER, Félix Gustavo. Explicación y predicción. La validez del conocimiento en ciencias sociales. Bs. As.: CLACSO, 2005 [1982].

TOZZI, Verónica. La historia según la nueva filosofía de la historia. Bs. As.: Prometeo Libros, 2009a.

El debate sobre el tipo de explicación en la disciplina histórica en la filosofía analítica de la historia. In: BRAUER, Daniel (ed.) La historia desde la teoría. Una guía de campo por el pensamiento filosófico acerca del sentido de la historia y del conocimiento del pasado. Vol. 1. Bs. As.: Prometeo Libros, 2009b.

VILAR, Pierre. Iniciación al vocabulario del análisis histórico. Barcelona: Crítica, 1980.

WHITE, Hayden. Metahistoria. La imaginación histórica en la Europa del siglo XIX. México: Fondo de Cultura Económica, 2010 [1973].

. El contenido de la forma. Narrativa, discurso y representación histórica. Barcelona: Editorial Paidós, 1992 [1987].

. El arte problematiza la memoria. Página 12, 23 jun. 2001.

. El texto histórico como artefacto literario. Barcelona: Paidós, 2003. 